\title{
Functional endoscopic sinus surgery for the management of sinonasal diseases
}

\author{
Kanu Lal Saha ${ }^{1}$, Ahmmad Taous², Md. Zillur Rahman ${ }^{3}$
}

\begin{abstract}
This study was carried out to observe the role and outcome of endoscopic sinus surgery in the management of sinonasal disease. Study was done in department of ENT \& Head-Neck Surgery, Dhaka Medical College, Dhaka from July 2002 to June 2004 (2 years). Sixty patients (60) were included retrospectively for this work. Main presenting symptoms of patients were nasal obstruction (78.33\%), nasal discharge (73.33\%), headache (51.66\%) and recurrent sore throat (50\%). In this series, minor complications occurred in 13.3\% which includes synechiae, haemorrhage, infection and eccymosis of eye. No major complications like CSF leak, retroorbital haemorrhage, blindness were noted. Only 3 cases (5\%) had severe haemorrohage. Most of the patients have got complete symptomatic relief, 5 cases had no improvement. It was concluded that functional endoscopic sinus surgery (FESS) has provided a safe and efficient method for dealing with different sinonasal disease and can be performed with high success rate for alleviation of symptoms with negligible morbidity.
\end{abstract}

Key words: Functional endoscopic sinus surgery, sinonasal disease, complications.

\section{Introduction}

Endoscopy was born when D'Esoreux demonstrated an alcohol illuminated urothrescope at the Paris Exibition in 1853 and won prize. The development of electricity followed, and a distally illuminated, watercooled cystoscope created interest when developed by Leiter in 1879. Nitze's success in using this instrument stimulated Zaufal to use a modified cystoscope to examine the Eustachian tube orifice pernasally during the $1880 \mathrm{~s}_{-}{ }^{1}$. Nasal and sinus endoscopy was first performed by Hirchman in 1903 using a modified Nitze cystoscope which he used in the nasal cavity and in the maxillary sinus via a tooth socket. ${ }^{2}$ The introduction of nasal endoscope has revolutionized the planning and treatment of nose and paranasal sinus diseases.

In the 1960s Messerklinger began his work with endoscopic diagnosis and surgery of sinuses. In 1985, Stammberger, a protege of Messerklinger, gave the first course on endoscopic diagnosis and treatment

1. OSD, DGHS, Deputed in Dept. of ENT, BSMMU, Dhaka.

2. Registrar of ENT, Mymensingh Medical College Hospital, Mymensingh

3.. Professor and Head of the dept. of ENT, Khulna Medical College, Khulna

Address of correspondence : Dr. Kanu Lal Saha, Consultant (ENT), Sorkari Kormochari Hospital, Dhaka. in the United States. The term Functional Endoscopic Sinus Surgery (FESS) was coined by Kennedy in 1985. Kennedy, Stammberger and Zinreich (1996) were mainly responsible for the rapid dissemination of endoscopic sinus disease diagnosis and surgery for sinonasal diseases. ${ }^{3}$ Hilding and later Messerklinger demonstrated that the mucous blanket covering the epithelium was propelled in an organized pattern from within the sinus through natural ostium and then into the nose and nasopharynx. ${ }^{4}$ A study of Bassiouny et al. ${ }^{5}$ showed that maxillary sinus mucosa in chronic sinusitis returns normal with the improvement of ventilation and drainage of maxillary sinus following FESS.

The indications for functional endoscopic sinus surgery are recurrent acute sinusitis or chronic sinusitis that does not respond to medical therapy. Functional approach is not applicable to all diseases of the Nose and Sinuses. In addition, horizons of Endoscopic Nasal Surgery have grown far beyond FESS and now include other Nasal, Orbital and anterior skull base procedures such as nasal polyposis, endoscopic dacryocystorhinostomy, CSF leak repair, orbital decompression.

Functional endoscopic sinus surgery can be performed under local or general anaesthesia. Local anaesthesia with deep sedation is preferable because sensory information remains intact along the periorbital and skull base region. Other beneficial effects of local 
anesthesia are minimum bleeding during operation, less duration of hospital stay, less cost etc.

Through the work of Kennedy \& associates, Stammberger and others, endoscopic techniques of Messerklinger are now used during surgery. A significant component in the success of endoscopic surgery is meticulous cleaning of the surgical cavity. 6,7 Patients are seen frequently post-operatively to clean debris and clots, to avoid synechiae and to monitor healing. Long term post-operative follow-up upto 3 to 6 month is necessary to monitor healing.

In experienced hands reported complications of FESS are surprisingly few. The most common complications are orbital ecchymoses, hemorrhage and synechiae. The most catastrophic rare complication of FESS is blindness resulting from damage to optic nerve. Another major complication is CSF leak. Most complications of the endoscopic sinus surgery can be managed and preventable. The interest of endoscopic sinus surgery is gradually increasing day by day. Important innovations in radiology, instrumentation and philosophy have greatly contributed to our ability to diagnose and treat sinus diseases.

\section{Aims \& objectives}

1. To assess the nose and paranasal sinus diseases which can be treated by FESS.

2. To see the efficiency of FESS as the treatment of nose and paranasal sinus diseases.

3. To determine the preoperative and postoperative complications and its management and outcome.

\section{Methods}

Type of study : : Retrospective study

Sample : 60 (Sixty)

Duration of study : July 2002 to June 2004 (two years)

Place of study : Department of ENT \& Head Neck Surgery, Dhaka Medical College Hospital, Dhaka.

\section{Inclusion Criteria :}

i. Patients did not respond to adequate medical and conservative surgical treatment (Antral washout).

ii. Clinically and radiologically suggested sinonasal diseases such as chronic/recurrent acute sinusitis, nasal polypoisis, rhinosporidiosis, etc.
Exclusion criteria :

I. Malignant conditions of nose and paranasal sinuses.

ii. Deep fungal diseases

Data collection method : Hospital records

Data analysis : By manual calculator.

\section{Results}

Table-I

Presenting symptoms $(n=60)$.

\begin{tabular}{lcc}
\hline Complaints & No. of patients & Percentage (\%) \\
\hline Nasal obstruction & 47 & $78.33 \%$ \\
Nasal discharge & 44 & $73.33 \%$ \\
Post nasal drip & 31 & $51.67 \%$ \\
Headache & 38 & $63.33 \%$ \\
Sneezing & 19 & $31.66 \%$ \\
Facial pain & 10 & $16.66 \%$ \\
Smell disturbance & 20 & $33.33 \%$ \\
Recurrent sore throat & 30 & $50.0 \%$ \\
Snoring & 10 & $16.66 \%$ \\
Nasal Bleeding & 3 & $5.0 \%$ \\
\hline
\end{tabular}

Table-II

Findings in X-ray paranasal sinuses OM view $(n=60)$

\begin{tabular}{lcc}
\hline Findings & No. of patients & Percentage (\%) \\
\hline Opacity in antrum & 50 & $83.33 \%$ \\
Mucosal thickening & 45 & $75 \%$ \\
Mucosal retention cyst & 10 & $16.67 \%$ \\
Septal deviation & 10 & $16.67 \&$ \\
\hline
\end{tabular}

Main findings of $X$ - ray were opacity in maxillary antrum 50(83.33\%) and mucosal thickenings in $45(75 \%)$ cases.

Table-III

Findings of CT scan $(n=20)$.

\begin{tabular}{lcc}
\hline Findings & No. of patients & Percentage (\%) \\
\hline Mucosal thickening & 15 & $75 \%$ \\
Blocked OMC & 14 & $70 \%$ \\
Isodense shadow & 10 & $50 \%$ \\
Septal deviation & 7 & $35 \%$ \\
Paradoxical middle turbinate & 2 & $10 \%$ \\
Aggar nasi pneumatization & 1 & $5 \%$ \\
Concha bullosa & 1 & $5 \%$ \\
\hline
\end{tabular}


Findings of CT scan revealed mucosal thickening in 15(75\%) cases and blocked OMC (Osteomeatal complex) in $14(70 \%)$ cases.

Table-IV Indications of FESS $(n=60)$.

\begin{tabular}{lcc}
\hline Indications & No. of patients & Percentage (\%) \\
\hline Sinusitis (Chronic/ & 22 & $36.67 \%$ \\
Recurrent acute) & & \\
Ethmoidal polyp & 19 & $31.67 \%$ \\
Antrochoanal polyp & 12 & $20.0 \%$ \\
Rhinosporidiosis & 7 & $11.66 \%$ \\
\hline
\end{tabular}

Table-V

Complications of FESS $(n=60)$.

\begin{tabular}{|c|c|c|c|}
\hline \multicolumn{2}{|c|}{ Complications } & \multirow{2}{*}{$\begin{array}{c}\begin{array}{c}\text { No. of } \\
\text { patients }\end{array} \\
4\end{array}$} & \multirow{2}{*}{$\begin{array}{c}\begin{array}{c}\text { Percentage } \\
(\%)\end{array} \\
6.67 \%\end{array}$} \\
\hline Minor & Synechiae & & \\
\hline & Haemorrhage & 2 & $3.33 \%$ \\
\hline & Infection & 1 & $1.67 \%$ \\
\hline & Ecchymoses of eye & 1 & $1.67 \%$ \\
\hline \multirow[t]{4}{*}{ Major } & Severe haemorrhage & 3 & $5.0 \%$ \\
\hline & CSF leakage & 0 & $0.0 \%$ \\
\hline & Retro-orbital haemorrhag & ige 0 & $0.0 \%$ \\
\hline & Blindness & 0 & $0.0 \%$ \\
\hline
\end{tabular}

Table-VI

Outcome of FESS $(n=60)$.

\begin{tabular}{lcc}
\hline Relief of symptoms & No. of patients & Percentage (\%) \\
\hline Complete & 46 & $76.67 \%$ \\
Partial & 9 & $15.0 \%$ \\
No relief of symptoms & 5 & $8.33 \%$ \\
\hline
\end{tabular}

Table-VII

Post operative follow-up $(n=60)$

\begin{tabular}{lcc}
\hline Follow up & No. of patients & Percentages \\
\hline $1^{\text {st }} w \mathrm{k}$. & 60 & $100 \%$ \\
$2^{\text {nd }} \mathrm{wk}$ & 60 & $100 \%$ \\
$3^{\text {rd }} \mathrm{wk}$ & 58 & $96.67 \%$ \\
$1^{\text {st }}$ month & 56 & $93.33 \%$ \\
$2^{\text {nd }}$ month & 48 & $80 \%$ \\
$3^{\text {rd }}$ month & 31 & $51.66 \%$ \\
$6^{\text {th }}$ month & 23 & $38.33 \%$ \\
\hline
\end{tabular}

Table-VIII

Post operative follow-up findings $(n=60)$

\begin{tabular}{lcccccc}
\hline Follow up & Hemorrhage & Blood clot & Nasal obstruction & Crust & Synechiae & CSFleak \\
\hline $1^{\text {st }}$ wk. & 2 & 53 & 60 & 60 & Nil & Nil \\
$2^{\text {nd }}$ wk & Nil & 22 & 41 & 47 & 4 & Nil \\
$3^{\text {rd }}$ wk & Nil & Nil & 23 & 34 & 2 & Nil \\
$1^{\text {st }}$ month & Nil & Nil & 7 & 10 & 1 & Nil \\
$2^{\text {nd }}$ month & Nil & Nil & Nil & Nil & Nil & Nil \\
$3^{\text {rd }}$ month & Nil & Nil & Nil & Nil & Nil & Nil \\
$6^{\text {th }}$ month & Nil & Nil & Nil & Nil & Nil & Nil \\
\hline
\end{tabular}

Table-IX

Endoscopic findings during operation $(n=60)$.

\begin{tabular}{lcc}
\hline Findings & No. of patients & Percentage (\%) \\
\hline Septal deviation & 10 & $16.66 \%$ \\
Polyp & 29 & $48.33 \%$ \\
Marked enlargement of bullae & 3 & $5.0 \%$ \\
Coacha bullosa & 5 & $8.33 \%$ \\
Abnormal uncinate process & 7 & $11.66 \%$ \\
Accessory ostium & 5 & $8.33 \%$ \\
Pradoxical middle turbinate & 4 & $6.66 \%$ \\
Aggar nasi pneumatization & 3 & $5.0 \%$ \\
Inflammatory exudates & 20 & $33.33 \%$ \\
\hline
\end{tabular}




\section{Discussion}

In the present study majority (48.34\%) of patients were in the group of 21-40 years being consistent with the findings of Rahman et al and inconsistent with Venkatachalam. ${ }^{8}$ The ages range from 13 to 69 years with mean age of 35.12. The male to female ratio was $2: 1$, which is similar to some other series. ${ }^{9,10}$

The main presenting symptoms of the patients in the study included nasal obstruction (78.33\%), nasal discharge (73.33\%), headache (63.33\%), post nasal drip (51.66\%) and recurrent sore throat (50.\%). This result is consistent with findings of Rice ${ }^{11}$ and Mathews et $\mathrm{al}^{12}$ but inconsistent with the result of Gross et al. ${ }^{13}$.

The findings of plain X-ray were opacity in antrum (83.33\%), mucosal thickening (75\%), mucosal retention cyst (16.67\%) and septal deviation in $(16.67 \%)$ cases. This result was inconsistent with the study of Mistry RK ${ }^{14}$ where opacity in antrum was found in all cases. In this study, out of 60 patients preoperative CT scan were done in 20 cases where mucosal thickening were seen in 15 patients. This result was different to other studies ${ }^{9,15,16}$. Major indications for FESS were sinusitis (36.67\%), ethmoidal polyp (31.66\%), antrochoanal polyp (20\%) and rhinosporidosis (11.66\%). This was almost similar to authors ${ }^{16,17}$. But this result differs form a study of Levine $^{18}$ where ethmoidal polyp (52.40\%) and chronic sinusitis (47.6\%) topped the series.

In this study majority of the patients (70\%) were operated under local anaesthesia. The ratio between Local anaesthesia and General anaesthesia was 2.33:1. This result was similar with the results of Rahman MZ ${ }^{19}$ where LA:GA was 2.66:1 but dissimilar with results of the studies ${ }^{18,20,21,22}$. Alam MN et al performed most of cases under GA where GA:LA was 2.21:1. FESS under LA was much more comfortable because bleeding was less, with no hazards of GA The risks of serious complications like intracranial complications, orbital injury were less because this skull base periorbital region is very sensitive to pain. The patients operated under LA responded immediately whenever the sensitive structures were touched. ${ }^{23}$

In this series minor complications occurred in $8(13.33 \%)$ cases which included synechiae (6.67\%), haemorrhage (3.33\%), infection (1.67\%) and eccymoses of eye (1.67\%). Major complications like severe haemorrhage was recorded in 3 cases (5.0\%).
No life threatening complications such as CSF leak, retro-orbital haemorrhage, blindness were noted. Complications were similar with other reported series. In Gross at el ${ }^{22}$ reported $13.9 \%$ complications in their series. Stankiewicz ${ }^{24}$ reported a $29 \%$ complication rate in 90 patients operated upon, with 7 major and 19 minor complications. Schaefer reported 14\% minor and $0 \%$ major complications. Stammberger reported two cases of cerebrospinal fluid leak and no other major complications in 4000 cases. Wigand and Hoseman(1991) reported ten cases of crerbrospinal fluid leak, two cases of intracranial infection and one death over more than 1000 cases

Complete relief of symptoms was observed in 46 (76.67\%) patients and partial relief of symptoms in 5 cases (15.0\%). But no relief of symptoms found in 5 cases (8.33\%). This was similar with some studies ${ }^{16,17}$ but inconsistent with the study of Smith et al.,23,25 where complete relief of symptoms were recorded more than $80 \%$ cases. Endoscopic findings during operation were consistent with other studies. ${ }^{26,27,28}$ Majority of the patients (81.67\%) were released from the hospital within 24 hours of operations, as no life threatening complications were noted during operations. This result was near to similar with a study of Danielsen Arild ${ }^{23}$ where $90 \%$ patents were treated as day case basis. So the success was high and morbidity low in the series.

\section{Conclusion}

Functional endoscopic sinus surgery has provided a safe and efficient method for dealing with different sinonasal diseases. Most often surgery can be safely and effectively done under local anaesthesia. Nasal endoscopy provides an illuminated view into the nasal cavity so that sinonasal diseases can be managed with high success for alleviation of symptoms and improvement of disease with negligible morbidity. Post operative follow up is as important as surgery and should be tailored to each patients needs.

\section{References}

1. Abdullah M. Endoscopic Sinus Surgery-Recent Advancement in Oto-Rhino-Laryngological Practice. Sir Slimullah Medical College Journal, 2005; 13: 52-54

2. Kennedy DW, Zinreich J, Rosenbaum AE, Johns M. Functional Endoscopic Sinus Surgery. Theory and diagnostic evaluation. Arch Otolaryngol, 1985; 111:576-582 
3. Stankiewicz J. Endoscopic nasal and sinus surgery. Surgery of the paranasal sinuses. $2^{\text {nd }}$ edition; W.B. Saunders Company; 1991 pp-233224.

4. Kennedy DW, Roth M. Functional Endoscopic Sinus Surgery. Otorhinolaryngology: Head and Neck surgery. 15 $5^{\text {th }}$ edn. Willium \& Wilkins, 1996. pp-173-180

5. Bassiouny A, Atef AM, Raouf MA, Nasr SM. Ultrastructural ciliary changes of maxillary sinus mucosa following functional endoscopic sinus surgery: an image analysis quantitative study. Laryngol Otol, 2003; 117(4): 273-9

6. Lund VJ, Savy L, L Loyd G. Imaging for endoscopic sinus surgery in adults. The Journal of Laryngology and Otology, 2000; 114: 395-397.

7. Mackay IS \& Lund VJ. Endoscopic sinus surgery.In: Scott-Brown's Otolaryngology. sixth edition,vol-4,Butterworth-Heinemann.Oxford, 1997: pp 4/12/17-4/12/23

8. Ramalingam R, Ramalingam KK. A hand book of endoscopiec sinus surgery, Chennai, India 1998.

9. Stammbeger H. FESS- Endscopic Diagnosis and Surgery of the paranasal sinuses and Anterior Skull Base. The Messerklinger Technique and Advanced Applications from the Graz School. Endopress. Tuttlingen, Germany, 2003, p. 13.

10. Rahman $M Z$ et al. FESS - A Review of personal series of 207 cases. Journal of Dhaka Medical College, 2003; 12 (1): 56-59.

11. Venkatachalam VP, Anurag. Comparative evaluation of Functional Endoscopic Sinus surgery and conventional surgery in management of chronic sinusitis. JIMA, 2002;100(2):1

12. Shah Nishit J. Functional Endoscopic Sinus Surgery. Bombay Hospital and Medical Research Centre, Mumbai, Oct. 1999.

13. Rice DH. Endoscopic sinus surgery : results at 2 year follow up. Otolaryngol Head Neck Surgery, 1989, 101: 476-477.

14. Mathews BL, Smith LE, Jhones R, Miller C, Bookschmidt JK. Endoscopic sinus surgery: Outcome in 155 cases. Otolaryngol Head Neck Surgery, 1991; 104: 244-6.

15. Gross et al. Endoscopic sinus surgery complications in residency. Laryngoscope, 1997; 107: 1080-1085.
16. Arild D. Functional endoscopic sinus surgery on a day case out patient basis, Clin Otolaryngol, 1992, 17; 473-477.

17. Stankiewicz JA, Maywood IL. Complications of endoscopic intranasal ethmoidectomy. Laryngoscope, 1987; 97: 1270-1273

18. Smith LF, Brindley PC. Indications, evaluation complications and results of functional endoscopic sinus surgery in 200 patients. Otolaryngol Head Neck Surg, 1993; 108(6): 68896.

19. Lee WC, Tilak RK, Walter NN. Local and Regional anesthesia for functional endoscopic sinus surgery. Ann Otol. Rhinol Laryngol, 1997; 767-769.

20. Rontal M: Rontal E. Anon JB: An anatomic approach to local anesthesia for surgery of the nose of paranasal sinuses. Otolaryngol ClinNorth Am, 1997; 30(3): 403-20.

21. Mistry RK. Surgical management of chronic sinusitis, Dept. of Otolaryngology and Head Neck Surgery, Combined Military Hospital, Dhaka, Bangladesh, 2004.

22. B. Nitinvakarn B, Thanavivatanich $\mathrm{S}$, Sangil $\mathrm{N}$ Anatomical variations of the lateral nasal wall and sinuses. A CT study for endoscopic sinus surgery in Thai patients.J Med Assoc Thai, 2005; 88(6): 763-8

23. Rahman $\mathrm{MZ}$ et al. Functional endoscopic sinus surgery under local anesthesia, Bangladesh Journal of Otorhinolaryngology, 2002; 8(1): 11-16.

24. Levine, HL. Functional endoscopic sinus surgery : Evaluation, surgery and follow up of 250 patients, Laryngoscope, 1990; 100: 79-84.

25. Schaefer, SD, Manning, S. and Close, L.G: Endoscopic paranasal sinus surgery; Indications and Considerations. Laryngoscope, 1989; 99: 1-5.

26. Stammberger $\mathrm{H}$. and Wolf G: Headaches \& Sinus disease. The endoscopic approach. Ann. Otol Rhinol. Laryngol, 1989; 97: 3-23.

27. Wignad ME. and Hosemann W.G. Results of endoscopic sinus surgery of the paranasal sinuses and anterior skull base. Journal of Otololaryngology, 1991; 20: 385-390.

28. Kirtane MV, Patel H, Muranjan S. Microdebriders in Endoscopic Sinus Surgery. In: Challenges in Otolaryngology, $1^{\text {st }}$ ed. Jaypee Brothers, 2005; pp. 41-42. 